\title{
Olhares acerca da finitude em idosos
}

\author{
Mauro Trevisan*, Kenya Cristina Alves", Wellington Camilo de Resende", Zilma Aparecida de Oliveira*, \\ Jocelaine A. T. Trevisan" ${ }^{* * *}$, Vicente de Paula Faleiros ${ }^{*+*}$
}

\section{Resumo}

A morte em si não tem um conceito único, pois os sentimentos despertados são variados e dependem de cada indivíduo. Estudar as percepções acerca da finitude, em idosos, pode permitir aos profissionais de enfermagem entender seus próprios valores e crenças diante do processo de morrer e da morte, bem como suas atitudes e ações pautadas em questões do dia a dia, as quais influenciam sua vida pessoal e profissional. O objetivo do estudo foi analisar o processo de morte em idosos na perspectiva da enfermagem. A metodologia utilizada foi a qualitativa, a qual deu suporte à interpretação e à reflexão do problema da pesquisa, assim como propiciou a busca pelo objetivo delimitado. Diante da análise das teorias, compreende-se que os profissionais de enfermagem sensibilizam-se diante da morte dos pacientes idosos, demonstrando diversos sentimentos, por isso, ressalta-se a necessidade de políticas de humanização e de valorização que favoreçam melhores condições de trabalho para esses profissionais, no âmbito do trabalho com pacientes idosos. Vale lembrar que a temática precisa ser discutida com maior ênfase nos cursos da área de saúde, nas disciplinas de Psicologia, de Antropologia e Sociologia da Saúde, a respeito das questões relacionadas ao processo de finitude, de forma que possa contribuir com o profissional, possibilitando-lhe um trabalho mais objetivo e seguro com os pacientes.

Palavras-chave: Profissional. Enfermagem. Morte. Idosos.

\section{Introdução}

Enfrentar a transitoriedade da vida, nem sempre é fácil. Muitos, prendem-se ao passado e esquecem o presente, outros, demasiadamente presos ao futuro insistem em não aceitar o presente e a transição; apresentam dificuldades em aceitar a transmutação de valores.

Por ser o enfermeiro um dos profissionais responsáveis pela promoção do bem-estar e da saúde, da prevenção e da recuperação dos indivíduos, visando

* Professor Especialista em Direito Civil pela Universidade Paranaense (Unipar), atuando em Gestão e Orientação Escolar (Famatec). Mestre em Filosofia pela Pontifícia Universidade Católica do Paraná (PUCPR). Mestre em Gerontologia e doutorando em Psicologia pela Universidade Católica de Brasília (UCB-DF). E-mail: professormauro.trevisan@gmail.com.

** Graduandos do curso de Enfermagem da Faculdade LS, Taguatinda Sul (DF).

*** Graduada em História pela Universidade Paranaense (Unipar) e mestranda em História pela Universidade de Brasília (UNB).

**** Pós-Doutorado. Université de Montreal, UdeM, Canadá; Pós-Doutorado. Écoles des Hautes Études en Sciences Sociales. Doutorado em Sociologia. Université de Montreal, UdeM, Canadá. Docente do Programa de Mestrado e Doutorado em Psicologia da UCB.

$\rightarrow$ http://dx.doi.org/10.5335/rbceh.2013.3232 
à preservação da vida, a morte é uma realidade presente em sua rotina de trabalho. Essa labuta exige, do enfermeiro, um preparo acadêmico e psicológico. Ainda que se saiba que a morte faz parte da vida, que há diferentes formas de morrer, assim como, diferentes formas de perceber a morte dos outros, a realidade da proximidade do fim da existência humana é um fato que merece reflexão.

$O$ profissional de enfermagem é um dos poucos que assiste ao ser humano em todas as fases da vida, inclusive diante da possibilidade da morte. Geralmente, esse não está preparado para enfrentar a morte, nem lidar com seus próprios sentimentos, principalmente quando precisa ajudar ao paciente morrer com dignidade, pois, tanto o assistido, quanto a família procuram, nesse profissional, apoio e assistência.

As ciências da saúde, assim como as reflexões filosóficas e religiosas, são baseadas na experiência diária, afirmam que são características intrínsecas do ser humano o dualismo entre vida e morte. (SCHRAMM, 2002). Assim, busca-se responder a seguinte problemática: qual a importância dos cuidados de enfermagem no processo de finitude do idoso? Os profissionais de enfermagem estão realmente preparados para lidar com situações relacionadas ao processo de finitude?

Uma estratégia de saúde em relação aos cuidados com o idoso, diz respeito à construção da integralidade do cuidado à saúde desse, diante da implantação e do fortalecimento do cuidado básico, pela expansão e pela qualificação dos profissionais de enfermagem, com incorporação das ações programáticas estratégicas, favorecendo o atendimento realizado.

A morte é uma realidade sempre presente na rotina de trabalho dos profissionais de saúde. Nesse sentido, é também representada de formas distintas para cada um desses profissionais que em suas percepções assimilam de maneiras distintas.

A relevância desse trabalho está na reflexão a respeito do processo de morte e morrer, e no olhar para o processo de finitude do idoso, do ponto de vista dos cuidados que prezam pela promoção da vida, por meio da humanização desse ato.

Diante dos objetivos propostos, o artigo organiza-se de modo a apresentar a metodologia utilizada para a análise dos dados; as reflexões acerca dos aspectos teóricos, os quais buscaram contemplar os conhecimentos relacionados ao processo de morte do idoso e o olhar da enfermagem; ainda, as considerações finais que pretender expor a unidade entre as teorias examinadas e os saberes prévios dos acadêmicos acerca do tema de estudo.

\section{Materiais e métodos}

A revisão de literatura tem papel fundamental no fazer acadêmico, pois é por meio dessa que se situa o trabalho dentro da grande área de pesquisa da qual faz parte, contextualizando-o (SANTOS, 2006).

Assim, ao construirmos este artigo, optamos por fazer, a priori, uma leitura aprofundada e intensa dos textos selecionados. Estes foram escolhidos devido à relevância do tema para a esta pesquisa. 
A opção foi pela pesquisa bibliográfica e/ou pesquisa em fontes secundárias por tratar-se de um levantamento e uma revisão de artigos bibliográficos, de livros, de periódicos com o propósito de posicionarmo-nos como pesquisadores, em contato direto, com o que já foi escrito em relação ao tema (MARCONI; LAKATOS, 2008).

Para a efetivação e eficácia, analisamos, em um primeiro momento, 52 trabalhos acadêmicos, entre esses, artigos Lilacs, Scielo, periódicos e capítulos de livros, dentre os quais, 35 foram pré-selecionados por sua importância para esta pesquisa. Em um segundo momento, foram selecionados 29 artigos, eleitos por sua construção, relevância e atualidade.

\section{Contextualização histórica}

Nas palavras de Agostinho,

[...] embora nem tudo chegue à velhice, tudo perece. Logo, quando nascem e esforçam-se por existir, quanto mais depressa crescem para existir, tanto mais se apressam para não existir. Essa é sua condição [...] (Confissões IV, 10, 1997).

Tal discussão mostra-se pertinente, conduz a pensarmos o ciclo da vida. No momento em que nascemos, já começamos a envelhecer, embora não aprendamos, dessa forma, em nossa cultura. Nem tão pouco somos motivados a pensar nisso, pois pensar na finitude poderia gerar angústia.

Segundo Trevisan (2012), no século $\mathrm{XX}$, o envelhecimento tornou-se um desafio para a sociedade, seja no campo da medicina seja no campo social, como um meio de compreender determinados problemas e possíveis soluções para a vida dos idosos.

Na concepção de Almeida, Carvalho e Brandão (2011, p. 2):

A morte é um termo com diversos significados, mas pouco compreendida, mesmo nos dias de hoje. Sabe-se que a ciência demonstra-nos a fragilidade do ser humano frente à morte, sobretudo frente a sua própria morte. Assim, a morte faz parte do ciclo biológico do indivíduo, que nasce, cresce e morre, no entanto, percebe-se que a morte e o luto são negados em virtude da angústia $\mathrm{e}$ do medo que causam nas pessoas, ocorrendo à insegurança em relação ao desconhecido, do que há por vir.

Segundo dados de estudos recentes, Kuster e Bisogno (2010) explicitam que o conceito perceptível de morte, no meio social, passou por modificações nos últimos anos: de cessamento dos batimentos cardíacos, evento ou momento, passou a ser visto como um processo, um fenômeno progressivo. A esse conceito de morte, deve-se a revisão realizada pela medicina diante dos diversos fatores, dentre esses, destaca-se a capacidade de prolongamento da vida, pela medicina, por meios artificiais, por diversos motivos, sejam sociais, humanos ou econômicos.

A morte não é vista somente como um simples fator biológico, mas como um processo que se constrói no meio social, não se distinguindo de outras dimensões universais das relações sociais. Diante disso, compreende-se que a morte é um processo presente no cotidiano de cada indivíduo e, independente das causas, dos fatores ou das formas, na maioria das vezes, o grande cenário desse processo continua sendo, ainda, as instituições de saúde e hospitalares (GUTIERREZ; CIAMPONE, 2007). 
A morte foi transformada em tabu pelo mundo ocidental. Na maioria das vezes, costuma-se resguardar as crianças no enfrentamento de tal realidade. Muitas vezes, o assunto é banido das conversas cotidianas. A morte, ou mesmo a ideia de morrer, provoca sentimentos muito intensos, trazendo para o indivíduo medo, fuga e espanto (LUNARDI, et al., 2002).

Em estudos históricos apresentados recentemente, percebe-se que a morte é um fenômeno observado e estudado em vários campos do saber. Para a ciência, morrer significa não mais existir em função de uma patologia ou de uma fatalidade que levou à falência de seus órgãos vitais (MOREIRA, 2006).

De acordo com Py e Trein (2006), falar de envelhecimento e morte são dois temas que se aproximam, embora muitas pessoas não os aceitem, pelo fato de que a cultura é de lutar pela vida. Aceitar o envelhecimento não é uma situação comum, pois sabe-se que, nessa etapa da vida, muitas são as transformações que a acompanham, entre as quais a perspectiva de finitude da vida. Negar o processo de envelhecimento faz com que as pessoas tornem-se resistentes para lidar com e falar dessas mudanças, tentando, de forma consciente ou inconsciente, evitar o sofrimento e a dor.

De acordo com Buarque (2011), o processo de envelhecimento no mundo está, cada vez mais,acelerado. Diante das inúmeras preocupações em relação ao processo demográfico, a que mais chama atenção é o número elevado de pessoas com idade superior a 60 anos, que ultrapassa os 893 milhões de pesso- as, mas no meio do século este número poderá ultrapassar 2,4 bilhões.

$\mathrm{Na}$ concepção de Kalache, Veras e Ramos (2007), o processo de envelhecimento não é um caso isolado no Brasil, este é um fenômeno com o qual até mesmo os países mais ricos e poderosos buscam adaptar-se. Esse fator, que anteriormente era considerado um privilégio de poucos, atualmente tem sido a experiência de um grupo de sujeitos cada vez maior na sociedade e no mundo inteiro.

As ciências da saúde, assim como as reflexões filosóficas e religiosas, que tem como base a experiência diária, afirmam que são características intrínsecas do ser humano a vulnerabilidade e a morte, por estarem presentes em todos os seres vivos, os quais são sistemas vivos que habitam o mundo, em um determinado tempo e espaço; sujeitos, portanto, a um processo irreversível da experiência humana que se desenvolve ao nascer, crescer, decair e morrer (SCHRAMM, 2002).

Para Almeida, Carvalho e Brandão,

[...] a enfermagem geralmente é a primeira a lidar e "sentir" a morte do paciente, já que este se torna dependente de seus cuidados, que vão desde os mais simples, como escovar os dentes, até os mais complexos. Isso ocorre principalmente quando o paciente está na fase terminal (2011, p. 2).

Como corrobora Cândido (2009), estudar as percepções culturais do método saúde-doença-morte, nas distintas sociedades, pode permitir aos profissionais de enfermagem entender seus próprios valores e crenças diante do processo de finitude.

Conforme concepção de Dias (2004), a ciência moderna valoriza aquilo que 
pode ser comprovado, medido e transformado em números. Hoje, graças ao avanço tecnológico, é possível radiografar e verificar o tamanho de um coração, dosar uma enzima, isolar um vírus e uma bactéria, mas não se pode medir o tamanho do sofrimento quando se perde alguém.

Diante de tal fenômeno, sabendo que todos os seres vivos estão programados biologicamente à finitude, lidar com esse fato não é algo banal, exige preparo técnico e psicológico, para confrontar-se com o fim da existência humana. Na concepção de Almeida, Carvalho e Brandão:

A enfermagem, como parte integrante da sociedade convive diretamente com o ser humano em processo de adoecer e morrer. Esses profissionais possuem grande dificuldade em reconhecer os seus limites, com isso eles passam a utilizar mecanismos de defesa para negar um acontecimento natural e inevitável da vida, a morte (2011, p. 3).

\section{Caracterizando a terceira idade}

De acordo com Batker (2010), os estudos demográficos, realizados no Brasil, apontam que a curva de crescimento populacional sofreu inversão a partir da década de 1970 e o retrato do país jovem ficou cada vez mais distante, pois a massa em ascensão é de idosos.

Na concepção de Roach (2009), diante dos vários avanços tecnológicos na área da medicina, a expectativa para a perspectiva de vida, em 2040 , será de 82,8 anos para mulheres e 75,9 anos para os homens. O envelhecimento da população é um fenômeno mundial, e concebe-se que, no Brasil, a população com idade superior a 60 anos aumentou de tal forma que o colocará, no ano de 2025, em sexto lugar em número de idosos.

Para Camarano (2010), o aumento mais alto do contingente idoso é o resultado da alta fecundidade em tempos passados, conjuntamente à atual redução da mortalidade, alterando o ciclo de vida do indivíduo, as estruturas familiares e a sociedade.

A expressão terceira idade, recentemente e com observável rapidez, tomou conta do vocabulário brasileiro. A expressão, de acordo com Leme e Silva (2002), tem sua origem na França e foi implantada na década de 1970, das Universités du Troisième Âge, agrupada ao vocabulário anglo-saxão com a concepção das Universities of the Third Ate em Cambridge, na Inglaterra, no verão de 1981.

O uso corrente da expressão terceira idade, entre os pesquisadores que se interessam por estudos relacionados à velhice, não é explicado pela citação a uma idade cronológica breve, mas por ser essa uma forma de tratamento das pessoas que tem mais idade, ainda não adquirindo uma conotação depreciativa. A criação do termo terceira idade compreende-se como um fruto importante do processo crescente de socialização da gestão da velhice, esta vista, por muito tempo, como adequada à esfera privada e familiar, uma ação de previdência individual ou de associações filantrópicas, transformando-a em uma questão pública.

A terceira idade é percebida como um anexo de orientações e intervenções que se definiu e se implementou por meio do próprio aparelho de Estado e de outras organizações privadas. Como consequên- 
cia, várias tentativas de homogeneização das reproduções da velhice são funcionais e uma nova hierarquia cultural é produzida. A maioria dos sujeitos idosos, como um conjugado independente e coerente atribui outro retalhe à geografia social, autorizando a colocação de novos modelos de gestão em prática.

A terceira idade mostra Debert (1994), explana, metaforicamente, uma outra situação de vida, a qual não é vista como um sinônimo de decadência, pobreza e doença, mas como um momento privilegiado para atividades livres dos acanhamentos do mundo profissional e familiar. Com a ampliação da esperança de vida, a cada um dos seres humanos é dado o direito de vivenciar uma nova fase relativamente longa, um tempo de lazer em que são elaborados outros valores coletivos.

Para Lasch (2009), a criação da terceira idade, no contexto social, indica uma experiência excepcional do envelhecimento humano, na qual toda a compreensão não pode ser diminuída aos números de prolongamento da vida nas sociedades contemporâneas. Segundo o referido autor, essa invenção solicita a existência de uma "comunidade de aposentados" com peso satisfatório na sociedade, evidenciando disposição de saúde, independência financeira e outros meios adequados para tornar reais as perspectivas de que essa etapa da vida seja propícia à realização e à satisfação pessoal dos indivíduos.

As práticas pautadas para a terceira idade são referências de um novo tipo de sensibilidade relacionada à vida adulta e à experiência do envelhecimento. Os empregos da terceira idade consentem a altercação do caráter, provavelmente, libertário e das lógicas de exclusão que configuram especificamente a organização de mercados de consumo e a articulação de ações políticas.

Essas novas imagens do envelhecimento que seguem a constituição da terceira idade asseguram um espaço cada vez maior na mídia, que, em resposta ao crescente interesse da sociedade pelas metodologias de rejuvenescimento, vem desestabilizando organismos tradicionais de diferenciação no cerne do mundo dos experts e, ao mesmo tempo, abrindo novos campos para a articulação de questões políticas e para a composição de novos mercados de consumo.

Muitas são as iniciativas volvidas para a terceira idade, transformando o envelhecimento em uma experiência muito mais gratificante, porém, o sucesso dessas ações surpreendentes são proporcionais à precariedade dos diversificados mecanismos de que o ser humano dispõe para lidar com os problemas da velhice avançada. A imagem que se tem do envelhecimento, anexa à terceira idade, ainda não apresenta instrumentos que sejam capazes de enfrentar os diversos problemas submergidos na perda de capacidades cognitivas e de domínios físicos e emocionais, que condenam o velho e que são considerados fundamentais, na sociedade, para que um determinado indivíduo seja reconhecido como ser humano autônomo, capaz da realização do exercício pleno dos direitos de cidadania, segundo Simões (2010).

A solução dos inúmeros problemas relacionados à velhice avançada, nas 
reproduções gratificantes da terceira idade, deposita no centro do debate a demanda da solidariedade no contexto de gerações, de maneira especial, em um contexto em que o envelhecimento populacional transforma-se em um risco para a perpetuação da vida social. Como mostra-nos Simões (2010), cada sociedade tem o seu portfólio de riscos, que constitui uma convenção específica de confiança e de medo.

As novas imagens existentes no cotidiano do envelhecimento e as formas contemporâneas de gestão do processo da velhice, no conjunto brasileiro, são acionadas na revisão dos estereótipos nos quais as etapas mais adiantadas da vida são acertadas. Essas imagens oferecem, de certa forma, um quadro mais positivo do envelhecimento, que passa a ser idealizado como uma experiência heterogênea em que a doença física e o declínio mental, analisados como fenômenos naturais neste estágio da vida, são redefinidos como qualidades gerais que comprometem as pessoas em toda e qualquer idade.

De acordo com Silvestre (1996), o processo de envelhecimento é conceituado de diferentes maneiras e existem muitas explicações para tal. Porém, há, ainda, muita dificuldade para entendermos esse processo no meio social. O envelhecimento é, de certa forma, dinâmico e progressivo. Sempre haverá alterações fisiológicas, bioquímicas e psicológicas que serão ocasionadas da perda progressiva do indivíduo, da adequação ao meio e de uma maior vulnerabilidade deste ao ser surpreendido por patologias, muitas vezes sem cura. Não há ainda uma explicação definitiva a respeito do processo de envelhecimento, nem tão pouco, um método para que este processo não progrida.

Na concepção de Figueiredo (2006), o processo de envelhecimento demarca modificações expressivas de ordem individual, familiar e social, cada uma destas com seus significados e relevâncias. Ao envelhecer, o idoso e sua família modificam-se, adquirindo assentados direitos legais e perdendo outros, pelas várias dificuldades orgânicas e mentais causadas pelo envelhecimento.

Definições e causas da mortalidade no mundo

Segundo Farias e Buchalla (2010), as condições de saúde relacionadas às doenças, aos transtornos ou às lesões são classificadas na Classificação Estatística Internacional de Doenças e problemas relacionados à saúde, $10^{\mathrm{a}}$ revisão (CID 10), por meio de instrumentos estatísticos que monitoram as diferentes causas de morbidade em indivíduos e populações, a fim de conhecer as causas de morte e as doenças mais frequentes, em um cenário em que a expectativa de vida aumenta e a tecnologia ajuda a medicina a prolongar a vida humana.

De acordo com a United Nations (1982), as informações referentes à mortalidade têm um desempenho relevante no papel do planejamento local, regional e nacional. Dados relacionados à mortalidade colaboram na identificação da situação demográfica do país e permitem fazer inferências em relação ao futuro. A par da perspectiva demográfica, os dados referentes à mortalidade são medidas importantes das condições socioeconômicas e de saúde. Por seu intermédio, 
mostra-se o progresso em uma das áreas de maior preocupação do homem, qual seja a do prolongamento da vida e da prevenção da morte prematura.

Segundo Laurent e Hasiak (2008), as estatísticas de mortalidade dependem de numerosas variáveis, tais como, gênero, idade, estado civil, local de residência e ocorrência e ocupação, entre outras, as quais serão utilizadas para a elaboração de análises detalhadas. Além dessas variáveis, a causa da morte é uma das mais importantes formas de análise. A informação precisa de padrões de mortalidade conforme a causa de morte possibilita a pesquisa de eventuais fatores etiológicos e a tomada de decisões visando à prevenção desses fatores.

As chamadas estatísticas de mortalidade também constituem-se em indicadores muito sensíveis de diferenças existentes nas populações, possibilitando a identificação de grupos de maior risco, a fim de implementarem programas especiais de saúde e de desenvolvimento. São úteis, por outro lado, para a avaliação de resultados dos programas já realizados. Além disso, os padrões de mortalidade relacionam-se com outros aspectos sociais, tais como a capacidade de trabalho e a fertilidade (UNITED NATIONS, 1982).

O trabalho de identificação e atribuição de um código da Classificação Internacional de Doenças à causa básica é realizado pelo codificador de causas de morte, que, para tanto, recebe treinamento especializado em cursos apropriados. É um trabalho que está sujeito a falhas que podem prejudicar a qualidade da codificação, tais falhas deve-se a vá- rios fatores, como os ligados ao tipo de treinamento recebido, as diferenças de interpretação de relações causais entre afecções, aos esquecimento de considerar afecções ou de aplicar regras ou disposições de codificação, aos erros de registro de códigos e outros (SANTOS, 2009).

Nas palavras de Laurenti e Buchalla (2010), a uniformidade internacional na produção de estatísticas de mortalidade por uma única causa foi definida como "a causa básica da morte" e esta deve ser declarada pelo médico. Para que as estatísticas de mortalidade por causas múltiplas sejam comparáveis, devem estar incorporadas as definições:

- causas intervenientes - advém de diagnósticos de doenças de causas fundamentais, que, de forma clara, vêm especificadas quando há óbito de pacientes. De forma geral, a busca pelo conhecimento das doenças e pela prevenção destasnão é uma busca pelas causas da morte nem mesmo um meio de preveni-la. Porém, a causa dessa pode ocorrer por meio de uma determinada ação, como, por exemplo, os sinistros que são causas relevantes;

- causas condicionantes - provém de causas variadas, ocasionando a morte. Porém, diante de determinações internacionais, estas causas não são desveladas como condicionantes do óbito. Um exemplo de causa condicionante que leva à morte é a hipertensão arterial, ocasionando diversos outros problemas, considerados como causas intervenientes, declarando-o como causa básica do óbito do paciente; 
- causas contribuintes - neste contexto, consideram-se como causas contribuintes algumas doenças ou complicações que se apresentam como contribuintes para o óbito, informados no atestado de óbito, de forma clara, na parte II;

- causas associadas - consideram-se todas as condições que não se contemplam nas causas intervenientes, nas causas condicionantes ou nas causas contribuintes.

De acordo com Pessine (2008), são diversos os conceitos ou entendimentos que se referem à morte, mas, ao comparar diferentes conceitos, compreende-se que todos têm algo em comum, isto é, abordam a parada das funções vitais e o afastamento do corpo e da alma. Nos séculos decorridos, era avaliada como diagnóstico de morte a cessação da respiração e da função cardíaca. Na época presente, o critério usual utilizado é a avaliação da função cerebral, pois, com a melhoria da tecnologia, tornou-se possível sustentar as funções cardíacas e respiratórias por meio de aparelhos, como o respirador, até que se obtenha uma resposta das funções cerebrais.

Olhares da Enfermagem acerca da finitude

Conceitua-se enfermagem como a arte de cuidar, bem como a ciência que tem a essência e a especificidade do cuidado ao ser humano, ou de forma individual, ou familiar ou coletivamente, de modo holístico, desenvolvendo, de forma autônoma ou em equipe, atividades que possam promover proteção, prevenção e recuperação da saúde (VIEIRA, 2008).
A enfermagem é uma profissão reconhecida e regulamentada pelo Conselho Federal de Enfermagem (Cofen), por meio dos conselhos regionais, de acordo com a lei n. 7.498 , de 25 de junho de 1986. Reconhecem-se como categorias de enfermagem os enfermeiros, os técnicos, os auxiliares de enfermagem e as parteiras (VIEIRA, 2008).

A categorização da enfermagem não distancia o profissional de seus sentimentos e de suas emoções vividas em seu cotidiano de trabalho. Em relação aos seus sentimentos diante da morte, Rees (1983) explicita que o enfermeiro age a estes sentimentos desprendendo-se do doente e da própria morte, e, conscientemente ou inconscientemente, dirige sua atenção a seu trabalho, ao material, ao processo da patologia, até a conversas superficiais, com a finalidade de afastar expressões de medo e de morte.

Na concepção de Almeida, Carvalho e Brandão (2011, p. 3),

[...] a morte é um evento biológico que encerra uma vida. Nenhum outro evento vital é capaz de suscitar, nos seres humanos, mais pensamentos dirigidos pela emoção e por reações emocionais do que ela, seja no individuo que está morrendo, seja naqueles a sua volta.

A morte incomoda e desafia a autoridade absoluta humana e profissional, pois os profissionais da área da saúde são instruídos a cuidar da vida, mas não da morte. Prova deste acontecimento é que, na maior parte dos cursos de formação de profissionais da área da saúde, não há um estudo curricular que aborde o assunto de forma não defensiva ou biológica, oferecendo espaço para uma discussão das subjetividades. Quantas 
vezes ouvimos na enfermagem a frase "Não chore! Você não pode chorar, nem mostrar seus sentimentos em frente ao paciente" (DASTUR, 2002).

Na concepção de Bernieri e Hirdes,

[...] a partir do momento em que nos descobrimos finitos, passamos a compreender melhor a finitude do outro, ou seja, dos pacientes. A partir de então, deixamos de encarar a morte como um fracasso de nossa profissão e passamos a percebê-la como algo natural e destinado a todos (2007).

A função mais básica de cuidados paliativos destinada ao trabalho do enfermeiro é oferecer um "cuidado total ativo" aos pacientes e a seus familiares junto a uma equipe de saúde, em que a atuação profissional e qualificada é, sem dúvidas, um requisito imprescindível para um atendimento satisfatório. Os cuidados paliativos agregam o aspecto físico, emocional, social e espiritual de pacientes e de seus familiares quando a patologia já não responde ao tratamento terapêutico curativo e à perspectiva de vida (FARIA; PEREIRA, 2007).

O profissional de saúde é finito, como todo e qualquer ser humano, e também passa por intensos dilemas existenciais, no enfrentamento da morte, em seu dia a dia. Muitas vezes, esse profissional, ainda como acadêmico, não foi preparado para refletir a morte e o morrer, podendo ser pego de surpresa pelo pesar, e, mais, não oferecer uma assistência de qualidade, não conseguindo ajudar a pessoa que está morrendo ou sua família, em razão da morte configurar-se como um momento de grande sofrimento e fracasso da ação principal que é de se manter a vida.
Diante disso, Almeida, Carvalho e Brandão (2011, p. 3) ressaltam que

[...] a equipe de enfermagem, como todas as profissões da área da saúde, tem como metas a promoção, a manutenção e a recuperação da saúde, o que pode explicar, em parte, o desconforto de se estar diante de um paciente em processo de morte e morrer.

Em concepção à ideia do trabalho do enfermeiro diante do fenômeno da morte, é importante explicitar que a perda de uma pessoa é uma circunstância altamente estressante. Portanto, o luto é uma resposta normal ao enfrentamento desse estresse e não uma doença, visto ser um processo e não um estado. O luto é a revelação de reações a uma perda expressiva, pois há a quebra dos vínculos que as pessoas constituem umas com as outras.

$\mathrm{O}$ estudo deste artigo remete a voltarmos nossos olhares, enquanto acadêmicos do curso de Enfermagem, para o trabalho com pacientes idosos, principalmente no que se refere ao processo de morte e morrer.

Lidar com o sentimento da morte nunca foi nem tão pouco será algo fácil, mesmo para os profissionais de enfermagem, que desenvolvem seu trabalho pautando-se em manuais de enfermagem, estágios e práticas de cuidados humanizados. A teoria é totalmente avessa à prática. Mesmo com tantos conhecimentos, o profissional de enfermagem vê-se limitado diante do processo de morte de um idoso em uma unidade hospitalar, porque não se consegue manter o controle emocional diante dessa situação, compreendendo, pois, que a morte é a finitude da vida humana, seja em qual circunstância for. 


\section{Considerações finais}

Os sentimentos decorridos diante da morte de um idoso são difíceis, por incitarem a reflexão de algo que é próprio no homem: sua finitude. A morte é vista social e culturalmente como parte do processo de vida dos indivíduos. Isso foi diferente há algum tempo, em que a morte era vista como um castigo ou uma punição dos ancestrais aos que cometessem algum tipo de pecado. Essa cultura modificou-se ao longo da história, porém os sentimentos humanos continuam a existir de forma a não haver uma forma concreta de explicá-la.

Em uma visão cientifica, a morte é explicada como parte da vida, um processo natural, que se desenvolve gradualmente, sem uma fórmula para mudar essa realidade. Em parte, aceitar esse fato ameniza o sofrimento da família, bem como dos profissionais que lidam com essa realidade cotidianamente em unidades de saúde.

Os profissionais que realizam o atendimento ao idoso são responsáveis por orientar, sanar dúvidas pertinentes aos procedimentos, trazendo uma maior tranquilidade e segurança. Não esqueçamos, porém, de que aqueles também necessitam de um ambiente adequado para realizar seu trabalho.

Dessa forma, compreende-se a importância do trabalho do enfermeiro diante da humanização das políticas relacionadas à morte do idoso e aos seus processos, zelando pelo bem-estar tanto do paciente, quanto da família, que se limita a esperar por uma reação, seja esta positiva (recuperação) seja negativa (morte).
Enfatiza-se com este estudo que os profissionais de saúde são os que mais lutam contra a morte, mas sua formação e carreira são marcadas pelo afastamento desta. A morte não faz parte do programa de estudos nas faculdades e universidades, por vezes, é estudada nos cursos que contemplam a disciplina de Antropologia da Saúde.

$\mathrm{O}$ interesse pela escolha do tema deu-se pela percepção, enquanto alunos, da importância do processo de finitude. $\mathrm{E}$, cada vez, torna-se necessário que haja uma ampla discussão à respeito da morte e do morrer.

A pesquisa do tema serviu como forma de conscientização enquanto futuros profissionais da área de saúde, para que possamos valorizar, ainda mais, a pessoa idosa em seu processo de morte e morrer, e, se possível, que possamos mudar esse quadro de trabalho. Assim, faz-se necessário ser realizado, pelos futuros profissionais de enfermagem, o desenvolvimento de debates que possibilitarão um maior aprofundamento das questões vida e morte, que proporcionando aprendizagens nas quais os profissionais poderão desenvolver se realmente sentem-se capazes de lidar com esse tema. $\mathrm{O}$ autoconhecimento do profissional não se refere apenas a uma questão interna deste próprio sujeito, mas, sim, a um procedimento que o auxiliará na delimitação das possibilidades da sua atuação. 


\section{Looks about the finitude in elderly}

\section{Abstract}

Death itself has no single concept because the feelings aroused are varied and depend on each person. Studying the perceptions of finitude in the elderly may allow nurse practitioners understand their own values and beliefs on the death and dying process as well as their attitudes and actions based on day to day issues that influence your personal and professional life. The aim of the study was to analyze the process of death in elderly people in the nursing perspective. The methodology used in the research was qualitative, supporting the interpretation and reflection of the research problem, as well as seeking to achieve the defined goal. Based on the analysis of theories, it is understood that nursing professionals are sensitized on the death of the elderly patients, demonstrating many feelings about this reality - emphasizing the need for humanization policies that promote recovery and good working conditions for these professionals in the work with elderly patients. It is noteworthy that the issue needs to be discussed with emphasis on the health courses in the disciplines of psychology and anthropology, and sociology of these health issues related to the finiteness process in order to contribute to the professional enabling the same work more objectively and patients with safe.

Keywords: Professional. Nursing. Death. Seniors.

\section{Referências}

AgOstinho, S. Confissões. São Paulo: Nova Cultural, 1997.

ALMEIDA, A. V. de; CARVALHO, A. C. M.; BRANDÃO, G. M. O. do N. Sentimentos e percepções da equipe de enfermagem frente à morte e o processo de morrer na unidade de terapia intensiva. Rev enferm UFPE, Pernambuco, v. 5, n. 5, p. 1367-1373, ago. 2011. Disponível em: <www.revista.ufpe.br/revistaenfermagem/index.php/revista/.../473>. Acesso em: 13 mar. 2013.

BERNIERI, J.; HIRDES, A. O preparo dos acadêmicos de enfermagem brasileiros para vivenciarem o processo morte-morrer. Texto e Contexto - Enfermagem - enferm, Florianópolis, v. 16, n. 1, set. 2007. Disponível em: $<$ http://www.scielo.br/scielo.php?pid=S0104$-07072007000100011 \&$ script $=$ sci_arttext $>$. Acesso em: 16 mar. 2013.

BUARQUE, D. O envelhecimento da população preocupa pesquisadores. G1, São Paulo, 2011. Disponível em: <http://g1.globo.com/ mundo/noticia/2011/10/envelhecimento-da-populacao-mundial-preocupa-pesquisadores.html>. Acesso em: 13 jan. 2013.

CAMARANO, A. A. Envelhecimento da população brasileira: uma contribuição demográfica. Rio de Janeiro: IPEA, 2010. Disponível em: <http://www.ipea.gov.br>. Acesso em: 5 jan. 2013.

CÂNDIDO, J. A morte sob a ótica da Enfermagem. 2009. Disponível em: <http://artigos. netsaber.com.br/resumo_artigo_18237/artigo_sobre_a_morte_sob_a_\%C3\%93tica_da_ enfermagem >. Acesso em: 18 fev. 2013.

CERVO, A. L.; BERVIAN, P. A. Metodologia científica. 5. ed. São Paulo: Prentice Hall, 2002.

DASTUR, F. A morte: ensaio sobre a finitude. Rio de Janeiro: Bertrand, 2002.

DEBERT, G. G. Gênero e envelhecimento: os programas para a terceira idade e o movimento dos aposentados. Estudos Feministas, Rio de Janeiro, v. 2, n. 3, p. 33-51. mar. 1994.

DIAS, M. O. da S. Outras falas: feminismo e medicina na Bahia. 2004. Disponível em: $<$ http://vsites.unb.br/ih/his/gefem/labrys12/leituras/prefacio.htm>. Acesso em: 24 fev. 2013.

FARIA, M. D.; PEREIRA, M. S. Cuidados paliativos: o olhar do enfermeiro na assistência aos familiares de clientes fora de 
possibilidade terapêutica. São Paulo. Disponível em: <http://artigos.netsaber.com. br/resumo_artigo_2259/artigo_sobre_cuidados_paliativos__o_olhar_do_enfermeiro_na_assistencia_aos_familiares_de_clientes_fora_de_possibilidade_terapeutica $>$. Acesso em: 14 mar. 2013.

FARIAS, N.; BUCHALLA, C. M. A Classificação internacional de funcionalidade, incapacidade e saúde da Organização Mundial da Saúde: conceitos, usos e perspectivas. Rev. Bras. Epidemiol, São Paulo, v. 8, n. 2, p. 187- 193, fev. 2010.

FIGUEIREDO, D. Cuidados familiares ao idoso dependente. Lisboa: Climepsi. 2007.

GIL, Antonio Carlos. Como elaborar projetos de pesquisa. 3. ed. São Paulo: Atlas, 1998.

GUTIERREZ, B. A. O.; CIAMPONE, M. H. T. O processo de morrer e a morte no enfoque dos profissionais de enfermagem de UTIs. Revista escola enfermagem, São Paulo, v. 41, n. 4, p. 45-53, dez. 2007.

KALACHE, A.; VERAS, R. P.; RAMOS, L. R. Envelhecimento populacional: uma realidade brasileira. Rev. Saúde públ., São. Paulo, v. 21, n. 3, p. 211-24, maio, 2007. Disponível em: <http://www.scielo.br/pdf/rsp/v21n3/06. pdf>. Acesso em: 14 mar. 2013.

KUSTER, D. K.; BISOGNO, S. B. C. A percepção do enfermeiro diante da morte dos pacientes. Disc. Scientia, Santa Maria, v. 11, n. 1, p. 9-24, abr. 2010. Série Ciências da Saúde. Disponível em: <ites.unifra.br/Artigos/Área/CiênciasdaSaúde/2010/.../Default. aspx>. Acesso em: 22 mar. 2013.

LAURENTI, R.; HASIAK, C. M. Mortalidade entre mulheres em idade reprodutiva no $\mathrm{mu}$ nicípio de São Paulo. Brasil. 2008. Disponível em: <bvssp.icict.fiocruz.br/lildbi/docsonline/ get.php?id=1425>. Acesso em: 19 fev. 2013.

LAURENTI, R.; BUCHALLA, C. M. A elaboração da estatísticas de mortalidade segundo causas múltiplas. Revista Brasileira de Epidemiologia, Rio de Janeiro, v. 3, n. 1, p. 21-28,
2010, p. 19-27. Disponível em: <http://teses. icict.fiocruz.br/pdf/mayalgm.pdf $>$. Acesso em: 23 mar. 2013.

LASCH, C. Refúgio num mundo sem coração - a família: santuário ou instituição sitiada? Rio de janeiro: Paz e Terra, 2009.

LEME, L. E. G.; SILVA, P. S. C. P. O idoso e a família. In: PAPALEO NETTO, M. (Org.). Gerontologia: a velhice e o envelhecimento. em visão globalizada. São Paulo: Atheneu, 2002. p. 92-97,

LUNARDI FILHO, W. D. et al. Percepções e condutas dos profissionais de enfermagem frente ao processo de morrer e morte. Texto e Contexto. Enfermagem, Florianópolis, v. 10, n. 3 , p. 60-81, 2002.

MOREIRA, A. da C. A Morte: entre o público e o privado: reflexões para a prática profissional de enfermagem. Revista Enfermagem UERJ, Rio de Janeiro, v. 14, n. 3, p. 44-56, set. 2006. Disponível em: <http://www.portalbvsenf.eerp.usp.br/ scielo.php?script $=$ sci_arttext\&pid $=$ S014$-35522006666300019 \& \operatorname{lng}=$ pt\&nrm $=$ iso $>$. Acesso em: 27 jan. 2013.

PESSINI, L. Bioética e cuidado do bem-estar humano: ética, humanização e vocação como desafio para os profissionais de saúde [online]. Rev Bioética, 2005. Disponível em: $<$ http://www.redadultosmayores.com.ar/ buscador/files/BIOET004.pdf>. Acessado em: 14 mar. 2013.

PY, L.; TREIN, F. Finitude e infinitude: dimensões do tempo na experiência do envelhecimento. In: FREITAS, E. V. et al. (Orgs.). Tratado de geriatria e gerontologia. Rio de Janeiro: Guanabara-Koogan; 2006. p.1353-1360.

REES, B. Enfermagens e grupos. Cadernos de Saúde Pública, Rio de Janeiro: 1983. Disponível em: <bvssp.icict.fiocruz.br/lildbi/ docsonline/get.php?id=1425>. Acesso em: 18 out. 2010. 
SANTOS, A. H. Causas múltiplas de morte: formas de apresentação e métodos de análise. São Paulo, 2009.

SCHRAMM, F. R. Morte e finitude em nossa sociedade: implicações no ensino dos cuidados paliativos. Revista Brasileira de Cancerologia, São Paulo, v. 1, n. 48, 2002, p. 17-20, jan./mar. Disponível em: <http://www. inca.gov.br/rbc/n_48/v01/pdf/opiniao.pdf>. Acesso em: 12 mar. 2013.

SILVESTRE, J. A. et al. O envelhecimento populacional brasileiro e o setor saúde. Arquivos de Geriatria e Gerontologia. n. 1, p. 81-89, set. 1996.

SIMÕES, J. A. O aposentado como ator político. ANPOCS, GT Cultura e Política, 2010.

TREVISAN, Mauro. O sentido da vida para os idosos: uma leitura existencial à luz da teoria de Viktor Frankl. 2012. Dissertação (Mestrado em Gerontologia) -Universidade Católica de Brasília, Brasília, 2012.

UNITED NATIONS. Department of international economic and social affairs. Levels and trends of mortality since. A joint study by the United Nations and the World Health Organization. New York, 1982.

VERGARA, S. C. Projetos e relatórios de pesquisa em administração. 7. ed. São Paulo: Atlas, 2006.

VIEIRA, A. L. S. Os enfermeiros e o Mercosul: regulamentação e controle do exercício profissional. 1998 (2008). Revista Brasileira de Enfermagem, Rio de Janeiro, v. 51, n. 1, p. 123-138, jan./mar. 1998. Disponível em: <www.ensp.fiocruz.br/observarh/arquivos/ artigo_reg.pdf>. Acesso em: 12 fev. 2013.

WORLD HEALTH ORGANIZATION (WHO). Cancer painl and paliative care. (Techinical report series 804). Geneva: World Health Organization, 1990. 